\title{
Correlation of Joint Roughness Coefficient (JRC) and Peak Friction Angles of Discontinuities of Malaysian Schists
}

\author{
Abdul Ghani Rafek \\ Geology Programme, Faculty of Science and Technology, National University of Malaysia \\ 43600 UKM Bangi, Selangor D. E., Malaysia \\ Tel: 60-389-215-668_E-mail: ghanirafekabdul@yahoo.com \\ Thian Lai Goh \\ MMV, EPTC Petronas, Etiqa Tower 1, Jalan Pinang, Kuala Lumpur, Malaysia \\ Tel: 60-390-193-141 E-mail: goh_thianlai@petronas.com.my
}

Received: September 7, 2011 Accepted: September 23, $2011 \quad$ Published: February 1, 2012

doi:10.5539/esr.v1n1p57 URL: http://dx.doi.org/10.5539/esr.v1n1p57

The research is financed by Government of Malaysia. Grant No. UKM-ST-02-FRGS-0023-2007.

\begin{abstract}
The surface roughness of geological discontinuities plays an important role in influencing the stability of rock masses. Several approaches can be adopted for its determination. This paper presents a simple approach whereby two polynomial approximations have been derived to correlate the peak friction angle, $\phi_{\text {peak }}$ of discontinuity planes of fresh as well as slightly weathered schist bedrock with the Joint Roughness Coefficient, JRC. These polynomial approximations are $\phi_{\text {peak }}=-0.022 \mathrm{JRC}^{2}+3.21 \mathrm{JRC}+28.1$ for fresh discontinuities and $\phi_{\text {peak }}=$ $-0.025 \mathrm{JRC}^{2}+3.24 \mathrm{JRC}+26.6$ for slightly weathered discontinuities, both with coefficient of determination $\left(\mathrm{R}^{2}\right)$ of 0.98 . These results offer an alternative method for estimation of the peak friction angle, $\phi_{\text {peak }}$ by measuring the JRC values in a field survey and employing these equations for the estimation of the peak friction angles of the discontinuity planes of cut rock slopes.
\end{abstract}

Keywords: JRC measurement, Peak friction angle of discontinuities, Tilt test

\section{Introduction}

Discontinuities play a predominant role in influencing the stability of rock masses, both for cut rock slopes as well as in underground excavations. In this context, the frictional characteristics of the discontinuity plane surfaces are of considerable importance. A number of different approaches can be adopted for the determination of this parameter. One of the earliest approach was by Fecker and Rengers (1971) employing a disc-clinometer and geological compass to estimate large scale discontinuity surface roughness. Patton (1966) determined the basic friction angle $\left(\phi_{\mathrm{b}}\right)$ and dilation angle (i) of saw-tooth samples with direct shear testing and concluded that the dilation angle is the first order roughness of the samples. The basic friction angle is the angle of friction of smooth planar sliding surfaces. The dilation angle is the angle of inclination to the shear stress direction due to surface irregularities and visible roughness. Barton (1973) also suggested that the second order roughness play an important role in Patton equation especially at low normal stress. Therefore, Barton (1973) proposed the values of $\left(\phi_{b}+i\right)$ for limestone, shale, quartzite, gneiss granite and amphibolite discontinuities at conditions of low normal stress. The value of $\left(\phi_{\mathrm{b}}+\mathrm{i}\right)$ represents the peak friction angle $\left(\phi_{\text {peak }}\right)$ of discontinuities surface roughness. Barton and Choubey (1977) suggested a method to estimate $\phi_{\text {peak }}$ from JRC, joint wall compression strength, $\phi_{b}$ and normal stress. Zhao (1997a, 1997b) introduced the concept of joint matching coefficient, JMC, based on his observations on the percentage of contact area between upper part and lower part of the discontinuity wall. Goh et al. (2011) determined $\phi_{\mathrm{b}}$ of artificially sawn granite discontinuity plane surfaces with the direct shear test. These methods proposed by Patton (1966), Barton (1973) as well as Goh et al. (2011) involve somewhat expensive laboratory testing apparatus, tedious sample preparation and testing procedures. In this study, a simple, low budget approach has been adopted, primarily to test the possibility of quantification of 
the surface roughness of discontinuities that can be used in the field at an early stage of engineering geological investigations without the need for expensive equipment and sophisticated testing procedures. The determination of the joint roughness coefficient and the corresponding peak friction angle, $\phi_{\text {peak }}$ were used to determine a relationship between these two parameters so as to enable an estimation of the peak friction angle, $\phi_{\text {peak }}$ based on joint roughness measurements in the field.

\section{Materials and Method}

Rock blocks containing natural discontinuity planes were collected from the different test sites and carefully separated into two blocks (upper and lower block) along the natural discontinuities. The surface roughness of these planes was measured using a comb profiler (Figure 1) in four different directions as recommended by Barton and Choubey (1977) with the determination of the Joint Roughness Coefficient values as shown in Figure 2. A simple self-fabricated tilt testing apparatus, modeled after Priest (1993) was employed (Figure 3) to measure peak friction angle, $\phi_{\text {peak }}$ of these discontinuity planes surfaces. The rock blocks containing upper and lower blocks were positioned in the tilt testing apparatus. The rock blocks were inclined from the horizontal position until the upper block slides and the inclination angle was measured with a clinometer. The tilt testing was repeated five times for each direction to reduce possible errors during inclination measurements. The tilt angles of these blocks were measured in four different directions because the value of JRC for each direction can vary. The tilt test results which were caused by toppling were discarded from the statistics. To minimize the possibility of toppling, the test blocks were prepared with an elongated shape. Test sites were selected to represent typical metamorphic rocks, predominantly schists that have widespread occurrence in Peninsula Malaysia. Figure 4 shows the locations of the different study sites- Ukay Perdana, Ulu Klang, Selangor, along the road of Kuala Kubu Baru - Bukit Fraser, Selangor (km 15) and the road of Pos Selim to Kg. Raja, Cameron Highlands, Pahang/Perak (km18-19 and km 21-26). From all these sites, rock blocks of both fresh and slightly weathered rock material containing natural discontinuities were collected using hand tools such as geological hammers of different sizes, chisels and picks. The weathering grade of rock samples were described according to ISRM (1981) description criteria and further quantified by using the Schmidt hammer rebound test as suggested by Hariri et al. (2009).

The lithology of Ukay Perdana, Ulu Klang can be described as graphitic mica quartz schist with an early Paleozoic (Cambrian - Ordovician) age (Gobbett, 1964). The rock type at the Kuala Kubu Baru- Bukit Fraser road (km 15) is a roof pendant of amphibolite schist within the granite of the Main Range of Peninsular Malaysia. Along the Pos Selim-Kg. Raja road (km 18-19 and 21-26) graphitic mica schist, quartz mica schist as well as mica schists occur.

\section{Results and Discussion}

A total of 2200 and 2150 tilt tests were conducted for fresh and slightly weathered schist samples respectively. The weathering characterization and classification was based on the recommendations of the International Society for Rock Mechanics, ISRM, as outlined in ISRM (1981). Grade I rock material is fresh, with no discoloration being observed. For Grade II, discoloration along discontinuity planes is clearly visible, and the rock material itself appears "faded", especially for the finer grain metamorphic rocks. The Joint Roughness Coefficients, JRC were also determined for all the natural discontinuity planes that were subjected to tilt testing. The results of testing are summarized in Table 1. The measured differences of the determined JRC values are within a $-4.1^{\circ}$ to $+1.8^{\circ}$ range for fresh discontinuities when compared with slightly weathered discontinuities for these sites underlain by schist bedrock.

The results of testing were analyzed at a 95\% confidence level using the statistical software package SPSS Version 16. The box plots of tilt tests with respective JRC values are shown in Figure 5.

The peak friction angle, $\phi_{\text {peak }}$ together with medians and skewness of the data distribution for fresh and slightly weathered natural schist discontinuities are shown in Table 1. Negative skewness implies more test results have of higher value for peak friction angle compared to the mean value. Positive skewness implies more test results have lower values of peak friction angles compared to the mean value.

Two polynomial approximations, $\phi_{\text {peak }}=-0.022 \mathrm{JRC}^{2}+3.21 \mathrm{JRC}+28.1$ and $\phi_{\text {peak }}=-0.025 \mathrm{JRC}^{2}+3.24 \mathrm{JRC}+26.6$ with coefficient of determination $\left(\mathrm{R}^{2}\right)$ of 0.98 had been established for both fresh and slightly weathered schist discontinuity plane surfaces respectively as illustrated in Figure 6. The value of JRC is taken as the mid point of respective JRC range. Both these approximations can be utilized to estimate the peak friction angle, $\phi_{\text {peak }}$ of the discontinuities surface without the need to conduct tilt testing. Table 2 presents examples of a comparison of the calculated values based on these equations with mean values from actual tilt test results. As can be seen from this table, the percentage difference between the tilt test determined values and the calculated value is less than $8.0 \%$. 
Therefore these equations offer an acceptable and valid means of estimating the peak friction angle of discontinuities from JRC measurements in the field for Malaysian Schists.

\section{Conclusion}

Two polynomial approximations, $\phi_{\text {peak }}=-0.022 \mathrm{JRC}^{2}+3.21 \mathrm{JRC}+28.1$ and $\phi_{\text {peak }}=-0.025 \mathrm{JRC}^{2}+3.24 \mathrm{JRC}+26.6$ with coefficient of determination $\left(\mathrm{R}^{2}\right)$ of 0.98 had been established for both fresh and slightly weathered discontinuity plane surfaces for schists from selected test sites in Peninsula Malaysia. These equations can be utilized for estimating the peak friction angle of discontinuities from JRC measurements in the field and offer a possibility of its quantification at a early stage of engineering geological investigation without the need of sampling and testing. These equations apply only to Malaysian schists at low normal stress levels and are expected to be useful at early stages of cut rock slope stability assessment.

\section{References}

Barton, N. \& Choubey, V. (1977). The shear strength of rock joints in theory and practice. Rock Mechanics, 10, 1-54. http://dx.doi.org/10.1007/BF01261801

Barton, N. (1973). Review of a new shear strength criterion for rock joints. Engineering Geology, 7, 287-332. http://dx.doi.org/10.1016/0013-7952(73)90013-6

Fecker, E. \& Rengers N. (1971). Measurement of large scale roughness of rock planes by means of profilograph and geological compass. Rock Fracture, Proc. of Int. Symp. Rock Mech Nancy, 1, 18.

Gobbett, D. J. (1964). The lower palaeozoic rocks of Kuala Lumpur, Malaysia. Fed. Museums Jour., 9, 67-70.

Goh, T. L., Ghani Rafek, A., Hariri Arifin, M., \& Baizura Yunus, N. (2011). Direct shear test of granite discontinuity plane surfaces. Sains Malaysiana, 40 (5), 419-423.

Hariri Arifin, M., Ghani Rafek, A., Goh, T. L., \& Baizura Yunus, N. (2009). The use of Schmidt rebound hammer as a method to estimate the degree of weathering for metamorphic rocks from Malaysia. Proceeding of Regional Conference on Environmental \& Earth Resources, 175-180.

ISRM. (1981). Rock characterization, testing and monitoring. ISRM Suggested Methods. Brown (Edt), Oxford : Pergamon Press, (Part 1).

Patton, F. D. (1966). Multiple modes of shear failure in rock. Proc. 1st International Congress of Rock Mechanics, Lisbon, 1, 509-513.

Priest, S. D. (1993). Discontinuity analysis for rock engineering. London: Chapman \& Hall, (Chapter 9). http://dx.doi.org/10.1007/978-94-011-1498-1

Zhao, J. (1997a). Joint surface matching and shear strength, Part A: joint matching coefficient (JMC). Int. J. Rock Mech. Min., 34 (2), 173-178. http://dx.doi.org/10.1016/S0148-9062(96)00062-9

Zhao, J. (1997b). Joint surface matching and shear strength, Part B: JRC-JMC shear strength criterion. Int. J. Rock Mech. Min., 34 (2), 179-185. http://dx.doi.org/10.1016/S0148-9062(96)00063-0 
Table 1. Summary of the statistical results of tilt testing for respective JRC values, Schist sites, Peninsula Malaysia

\begin{tabular}{|l|l|l|l|l|l|l|l|}
\hline $\begin{array}{c}\text { Weathering } \\
\text { Grade }\end{array}$ & $\begin{array}{c}\text { Midpoint } \\
\text { of JRC }\end{array}$ & No. of test & $\begin{array}{c}\text { Median } \\
\left({ }^{\circ}\right)\end{array}$ & $\begin{array}{c}\text { Standard } \\
\text { Deviation }\left(^{\circ}\right)\end{array}$ & $\begin{array}{c}\text { Mean } \\
\left({ }^{\circ}\right)\end{array}$ & Skewness & $\begin{array}{l}\text { Difference with } \\
\text { grade I }\left(^{\circ}\right)\end{array}$ \\
\hline \multirow{4}{*}{ I } & 1 & 920 & 30.0 & 2.2 & $29.6 \pm 0.1$ & negative & - \\
\cline { 2 - 8 } & 3 & 130 & 38.0 & 3.4 & $37.9 \pm 0.6$ & normal & - \\
\cline { 2 - 8 } & 5 & 110 & 42.0 & 6.1 & $44.3 \pm 1.2$ & positive & - \\
\cline { 2 - 8 } & 7 & 330 & 52.0 & 6.2 & $51.9 \pm 0.7$ & normal & - \\
\cline { 2 - 8 } & 9 & 140 & 57.0 & 5.1 & $56.6 \pm 0.8$ & negative & - \\
\cline { 2 - 8 } & 11 & 90 & 58.0 & 5.4 & $58.5 \pm 1.1$ & positive & - \\
\cline { 2 - 8 } & 13 & 140 & 68.0 & 5.5 & $67.5 \pm 0.9$ & positive & - \\
\cline { 2 - 8 } & 15 & 120 & 66.0 & 5.5 & $66.3 \pm 1.0$ & normal & - \\
\cline { 2 - 8 } & 19 & 220 & 84.0 & 5.2 & $83.3 \pm 0.7$ & negative & - \\
\hline \multirow{5}{*}{ II } & 1 & 1020 & 28.0 & 2.2 & $28.1 \pm 0.1$ & normal & -1.5 \\
\cline { 2 - 8 } & 3 & 50 & 38.0 & 3.1 & $38.3 \pm 0.9$ & normal & +0.4 \\
\cline { 2 - 8 } & 5 & 90 & 40.0 & 6.2 & $41.7 \pm 1.3$ & positive & -2.6 \\
\cline { 2 - 8 } & 7 & 180 & 49.0 & 7.6 & $49.6 \pm 1.1$ & positive & -2.3 \\
\cline { 2 - 8 } & 9 & 240 & 51.0 & 7.0 & $52.5 \pm 0.9$ & positive & -4.1 \\
\cline { 2 - 8 } & 13 & 140 & 66.0 & 8.9 & $66.9 \pm 1.5$ & positive & -0.6 \\
\cline { 2 - 8 } & 15 & 40 & 68.0 & 5.1 & $68.1 \pm 1.6$ & normal & +1.8 \\
\cline { 2 - 8 } & 17 & 130 & 70.0 & 8.3 & $70.4 \pm 1.4$ & positive & - \\
\cline { 2 - 8 } & 19 & 260 & 82.0 & 5.8 & $82.3 \pm 0.7$ & normal & -1.0 \\
\hline
\end{tabular}

Table 2. Comparison of calculated and measured peak friction angles with measured JRC values

\begin{tabular}{|l|l|l|l|l|l|l|l|l|l|l|l|l|}
\hline Grade & Method/JRC & 0 & 1 & 3 & 5 & 7 & 9 & 11 & 13 & 15 & 17 & 19 \\
\hline \multirow{4}{*}{ I } & Tilt test & - & 29.6 & 37.9 & 44.3 & 51.9 & 56.6 & 58.5 & 67.5 & 66.3 & - & 83.3 \\
\cline { 2 - 11 } & $\begin{array}{l}\phi_{\text {peak }}=-0.022 J_{R C}{ }^{2} \\
+3.21 \mathrm{JRC}+28.1\end{array}$ & 28.1 & 31.3 & 37.5 & 43.6 & 49.5 & 55.2 & 60.7 & 66.0 & 71.2 & 76.2 & 81.0 \\
\cline { 2 - 12 } & Difference (\%) & - & -5.80 & 0.98 & 1.55 & 4.60 & 2.57 & -3.69 & 2.19 & -7.32 & - & 2.83 \\
\hline \multirow{4}{*}{ II } & Tilt test & - & 28.1 & 38.3 & 41.7 & 49.6 & 52.5 & - & 66.9 & 68.1 & 70.4 & 82.3 \\
\cline { 2 - 11 } & $\begin{array}{l}\phi_{\text {peak }}=-0.025 J_{R C}{ }^{2} \\
+3.24 J R C+26.6\end{array}$ & 26.6 & 29.9 & 36.1 & 42.2 & 48.1 & 53.8 & 59.3 & 64.5 & 69.6 & 74.5 & 79.2 \\
\cline { 2 - 11 } & Difference (\%) & - & -6.26 & 5.54 & -1.35 & 3.04 & -2.38 & - & 3.48 & -2.22 & -5.79 & 3.82 \\
\hline
\end{tabular}




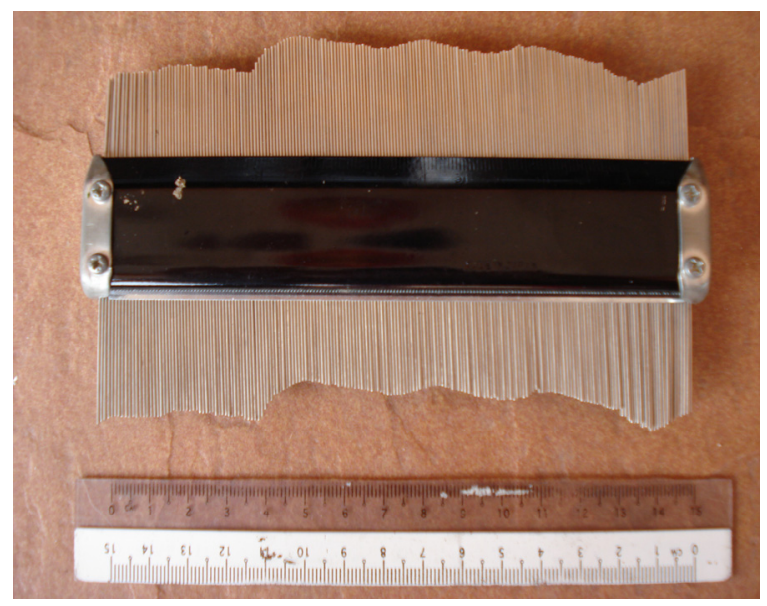

Figure 1. Standard $15 \mathrm{~cm}$ JRC comb profiler employed in this study

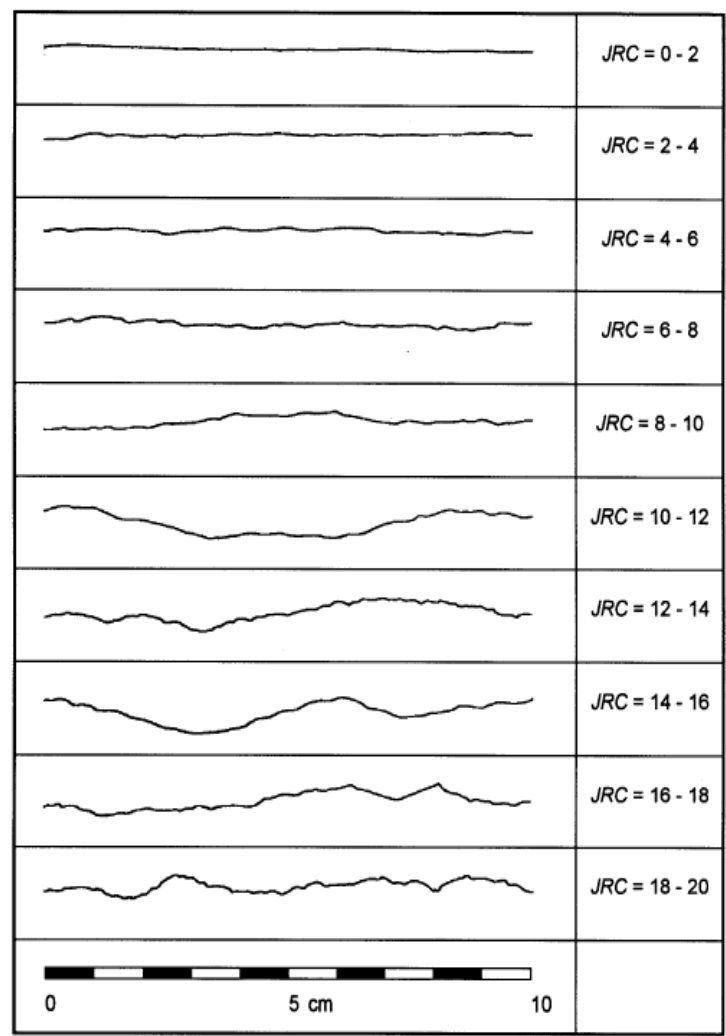

Figure 2. Joint Roughness Coeficient, JRC for different surface roughness profile, according to Barton and Choubey (1977) 


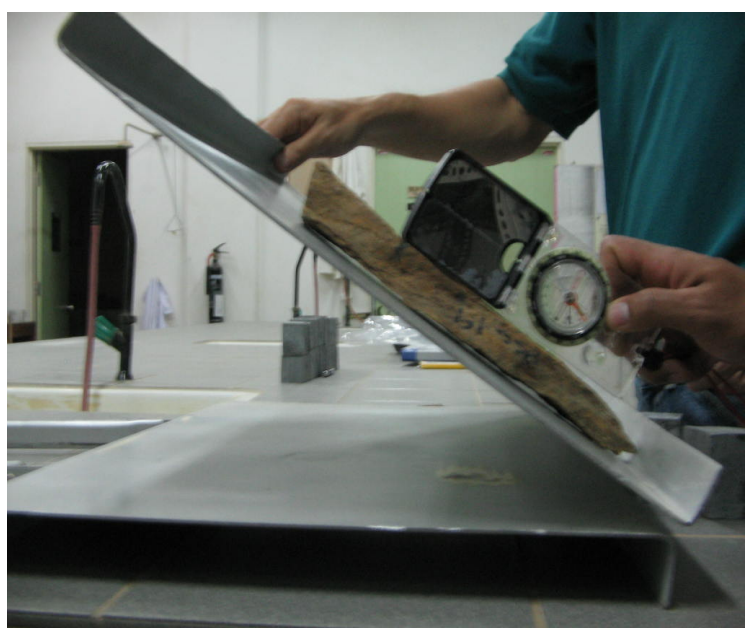

Figure 3. A simple self-fabricated apparatus, modeled after Priest (1993) employed for the determination of peak friction angle, $\phi_{\text {peak }}$

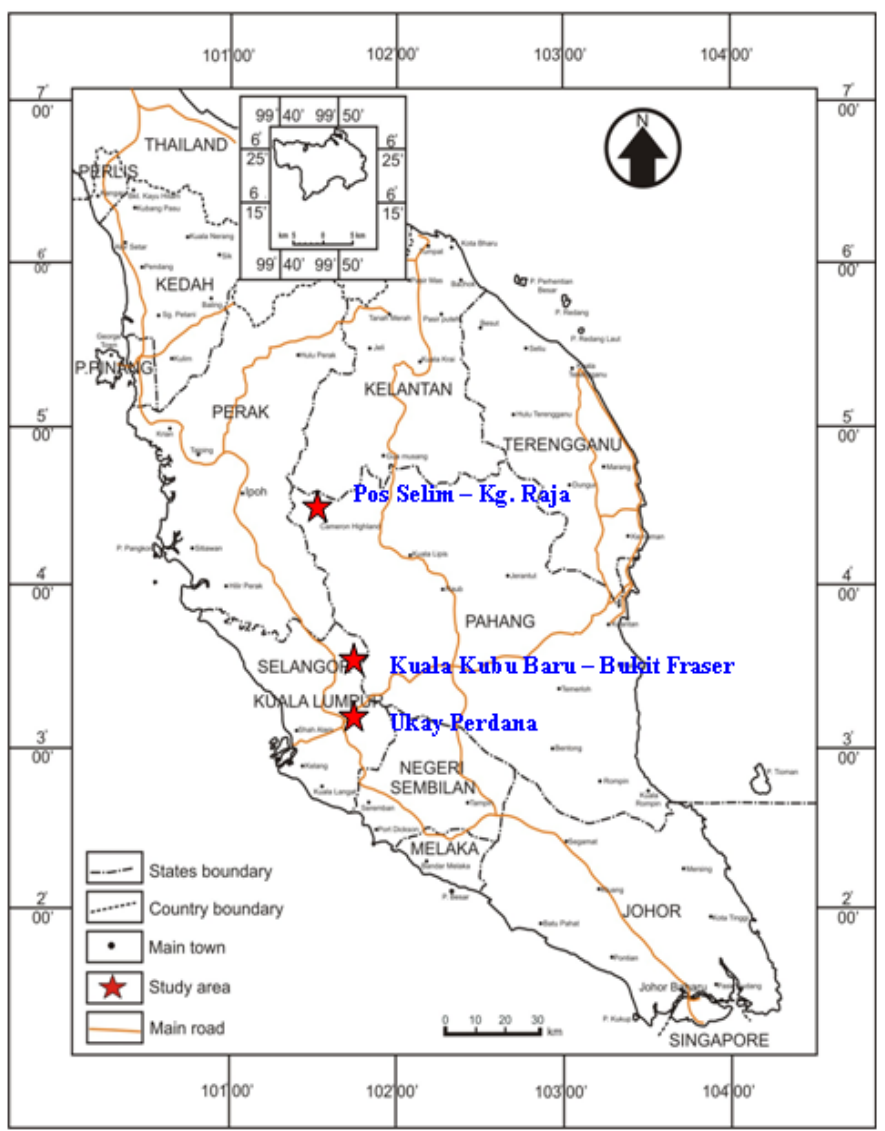

Figure 4. Location of test sites, Peninsula Malaysia 

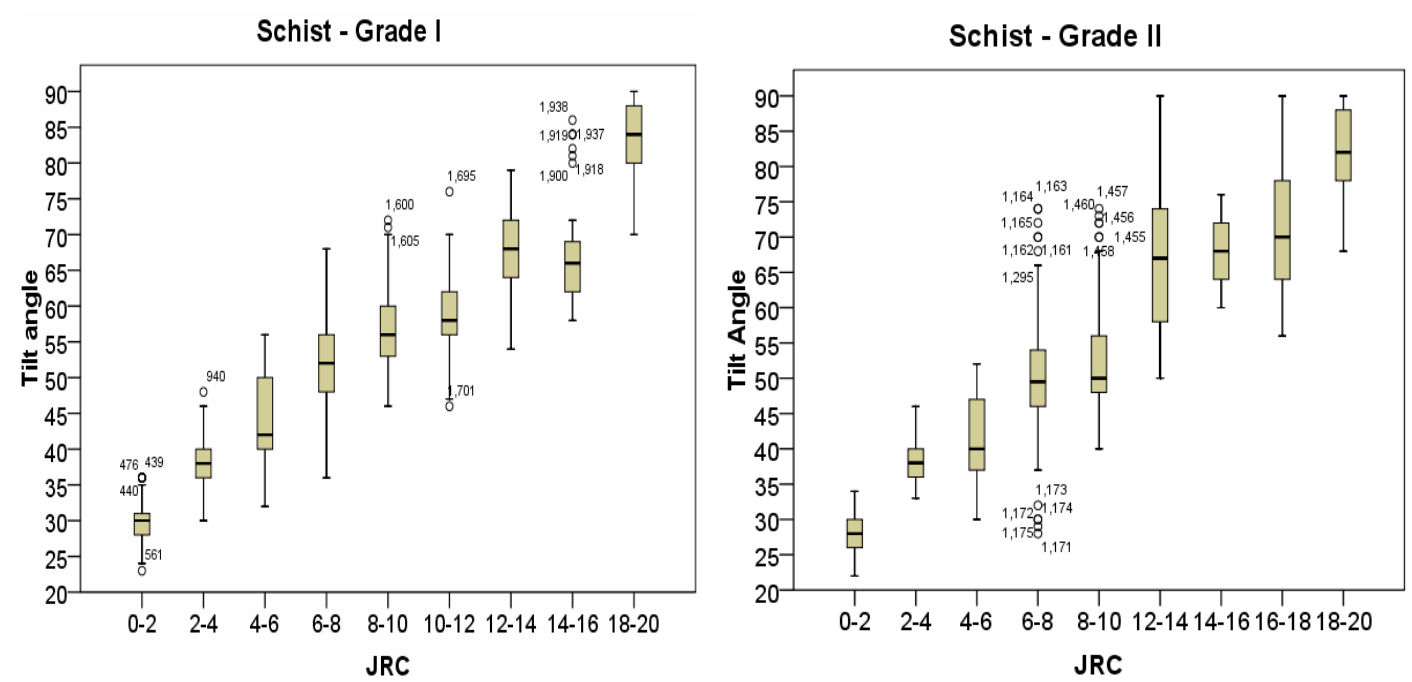

Figure 5. Boxplot of tilt test results for respective JRC
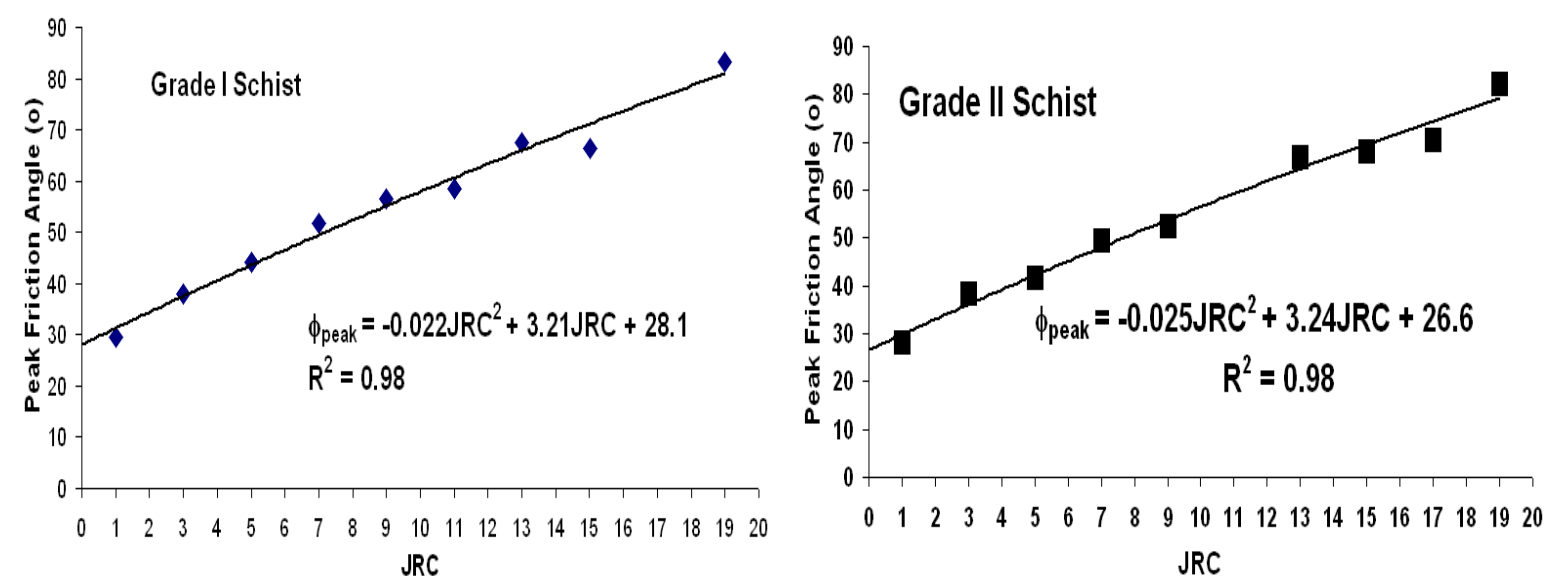

Figure 6. Two polynomial approximations obtained from peak friction angle versus JRC for fresh (Grade I) and slightly weathered (Grade II) Schist, Peninsula Malaysia 